\title{
Spatial and Temporal Occurrence and Effects of Droughts on Crop Yields in Kenya
}

\author{
Jackob H. Ondiko, Amon M. Karanja \\ Department of Geography, Egerton University, Njoro, Kenya \\ Email: ondikojackob2018@gmail.com, amon.karanja@egerton.ac.ke
}

How to cite this paper: Ondiko, J. H. and Karanja, A. M. (2021) Spatial and Temporal Occurrence and Effects of Droughts on Crop Yields in Kenya. Open Access Library Journal, 8: e7354.

https://doi.org/10.4236/oalib.1107354

Received: March 26, 2021

Accepted: June 18, 2021

Published: June 21, 2021

Copyright $\odot 2021$ by author(s) and Open Access Library Inc.

This work is licensed under the Creative Commons Attribution International License (CC BY 4.0).

http://creativecommons.org/licenses/by/4.0/

(c) (i) Open Access

\begin{abstract}
Increase in drought frequency, magnitude and duration affect crop production in Kenya. The limited food production resulting from drought leads to food insecurity in Arid and Semi-Arid Lands (ASALs) in the Kenya. This study reviewed literature on drought trends and its effects on crop yields in Kenya from 1950 to 2020. The systematic review was conducted in order to establish the drought trends and the effects of droughts on crop yields in the country. Content analysis was used for literature review on drought trends and its effects on maize, sorghum and wheat production in Kenya. From the study, a high uncertainty in global-scale drought trends in the last 60 years was established. However, an increase in drought frequency was observed from 1950 to 2002 in Africa. Few drought events were experienced in 1950s with a notable positive trend in drought frequency observed in 1960s in Kenya. In 1970s, an increased frequency and severity of droughts were observed while a decline in drought frequency was noted in 1980s. More frequent and severe droughts in Kenya were also established to have occurred in 1990s and 2000s. However, a decline in drought frequency and severity was reported in 2010s. The severity of the droughts negatively affected crop production where food insecurity was experienced in different regions of the country. The study also found that drought leads to famine and loss of human lives. Loss of livelihood such as livestock was also identified. The study identified limited information on decadal causes and recurrence of droughts and inadequate explanation on why 1950 to 2020 experienced global uncertainty in drought occurrence.
\end{abstract}

\section{Subject Areas \\ Environmental Sciences, Geography}

\section{Keywords}

Drought, Drought Frequency, Climate Variability, 


\section{Introduction}

Drought is a natural cyclic climatic event exhibited by deficit in precipitation below the seasonal or annual statistical means in a given geographical region [1] and [2]. The deficit in seasonal and/or annual rainfall amounts is accompanied by high temperatures above the seasonal or annual statistical means. The variations in seasonal or annual precipitation amounts result in meteorological droughts. Meteorological droughts determine the occurrence of other kinds of droughts such as agricultural, hydrological and socioeconomic droughts. Therefore, occurrence, frequency, severity and duration of droughts are major challenges that affect crop production in Kenya. The non-existence of a comprehensive analysis of droughts and effects on physical, social environments and food production [3], creates the need for this systematic review. Even though, the effects of drought are experienced in $40 \%$ of the global surface area which is Arid and Semi-Arid Lands (ASALs) [4]; these regions have the potential to sustain drought resistant food crop production.

The IPCC predicted increase in global temperatures ranging from $0.3^{\circ} \mathrm{C}$ to $0.7^{\circ} \mathrm{C}$ in the coming two decades with increases of $0.3^{\circ} \mathrm{C}$ to $0.48^{\circ} \mathrm{C}$ by the end of the $21^{\text {st }}$ Century [5]. The predicted increase in temperatures is likely to influence the precipitation amounts and frequency and heat conditions in different regions of the world. These variations are also likely to be accompanied by increase in drought episodes. Further increased projections of $0.14^{\circ} \mathrm{C}$ to $5.8^{\circ} \mathrm{C}$ every decade with corresponding reductions in crop yields of $11 \%$ to $46 \%$ by 2050 were established [6]. The occurrence of frequent droughts with variable spatial extents that are accompanied by significant effects on crop production and yields in Kenya is a major concern. Additionally, the projected increase in drought episodes and subsequent significant impact on food crop production is also a major concern. This systematic review was therefore conducted in order to establish the spatial and temporal occurrence and effects of droughts on crop yields in Kenya.

Droughts are primarily driven by climate change and anthropogenic forcing [3]. Climate change leads to droughts through the variability of global precipitation and warming patterns. In addition, anthropogenic forcing, more particularly industrialization, transportation, energy generation, deforestation and urbanization increases the release of Greenhouse Gases into the atmosphere thereby influencing the temperature conditions. The increased warm conditions influenced occurrence of droughts. The severe droughts were also linked to the warming of $1.5^{\circ} \mathrm{C}$ to $2.0^{\circ} \mathrm{C}$ in different regions of the world [7]. The positive warming trends in different regions of the world influence the atmospheric conditions where decline in precipitation levels and meteorological droughts are 
recorded. The resulting variability in atmospheric temperatures influence atmospheric precipitation levels hence reduced rainfall in some regions of the world. Deficit in seasonal or annual rainfall amounts affects crop production where severe to extreme drought events lead to decline and even loss of crops. An increase in drought frequency was observed from 1950 to 2002 in Africa. In addition, [3] revealed prolonged, frequent and more severe drought trends in East Africa in the past two decades. The climatic variations are associated with increase in climate change and anthropogenic events in the region [7]. The drought events are also common phenomena mostly in the ASALs in the region.

An uncertain trend in global drought events was recorded in the past six decades [8]. Further, fluctuations in global drought trends with significant regional variations in frequency and severity were also recorded [9]. The notable significant fluctuations in global drought patterns affect food crop production despite the rapidly increasing demand due to increase in global population. On the other hand, Intergovernmental Panel on Climate Change [10] Assessment report (AR5) indicated an increase in droughts globally from 1979 to 2002. Meanwhile, the variations in climatic conditions exemplified by increase in temperatures were established to result in droughts [7]. In addition, a decline in precipitation and increase in net radiation also influence drought occurrence [9]. Even though fluctuations in drought severity and frequency from 1979 to 2013 were reported in USA, $62 \%$ of the country was affected by the 2012 drought which was shorter yet widespread, and billed as the most severe in the past five decades [9] and [11].

In the past five decades, Africa experienced severe droughts where continental droughts were experienced in 1960s, 1970s, 1980s and 1990s [12]. These drought events signal a decade return period. Increased frequency of draughts in Africa was also realized by the study which indicated a shorter periodicity of three to five years of return in the past two decades (1990s to 2010s). The study also noted occurrence of single to multi-year droughts in most African countries. An increase in frequency and severity of droughts in Sub Saharan Africa (SSA) was also projected [2] and [13]. Considering the rapidly increasing annual African population; fluctuations in food production results in food supply gap which is a major cause for concern. The deficit in food supply in SSA is further heightened by the rain-fed food production systems that are wholly dependent on rainfall, failure of which crop loss is recorded.

Significant decline in rainfall was recorded in the Horn of Africa (HOA) from 1950 to 1963 [14]. The study also revealed occurrence of severe droughts experienced in 1984 in the region. Longer, severe and frequent droughts were also recorded in 1950s, 1960s, 1980s and 1990s in Eritrea, Northwest Ethiopia and Eastern Somalia. Moreover, Ethiopia and Sudan recorded severe droughts in mid-1980s which resulted in the deaths of 450,000 people [3]. The resulting loss of lives limited the farm labour hence reduced food crop production in the region. Further, the region experienced severe droughts in 1980s, 2000s and 2010s 
[12] and [15]. The frequent droughts in the HOA have constrained crop production leading to food insecurity in the region.

East Africa was noted to experience a more frequent drought return period; once in three years from once in six years since 2005 [3]. The short drought return period and increased frequency of droughts in the region result in desiccated pedological conditions with precipitation deficits and increased heat conditions. These pedo-climatic constraints limit food crop production in East Africa.

In Kenya, droughts are common phenomena where $80 \%$ of the land is ASAL [16]. The ASALs experience low rainfall between 200 to 500 millimetres (mm) annually. Notably, Kenya experienced severe drought disasters in 1950s to 2010s [14]. Meanwhile, [17] noted that drought is a cyclical natural phenomenon whose recurrence was three to five years in Kenya. Further, single drought events were recorded annually from 1965 to 2008; however, multiple drought events were also registered in 2011 in Kenya [18]. The occurrences of meteorological droughts in ASALs lead to agricultural droughts that are exhibited by soil moisture deficit hence decline in crop yields. A high rate of vulnerability to droughts in Northern and Eastern Kenya with a probability of more than $40 \%$ chance of annual recurrence was realized [16]. Northern and Eastern regions fall within the ASALs in Kenya which experience low rainfall. Even though, the ASAL climatic conditions support the growth of drought tolerant crops such as sorghum, millet, maize, peas, beans and some fruits, slight variations in climatic conditions significantly influence the production of the crops. Development and occurrence of droughts may take a short to a long period of time. The elongated periods of drought development and durations lead to lags in water availability and constrained crop water use. The resulting water stress accompanied by heat stress lead to limitation of crop growth and development hence low yields. This study reviewed spatial and temporal occurrence and effects of droughts on crop yields in Kenya. A review of national drought trends was necessary to identify drought occurrence and effects and also lay a foundation for further studies on causes of droughts and projections of drought trends in the country.

\section{Drought Trends in Kenya (1950-2010)}

The largest part of the surface area in Kenya is ASAL covering $80 \%$ of the land [14]. These ASALs experience low rainfall of about $300 \mathrm{~mm}$ annually. The 1950s, 1980s, 1990s and 2000s were registered as having experienced droughts in Kenya [16] and [18]. The single to multi-year and three to five years drought recurrence period were also reported in the ASALs including Northeastern, Eastern, Coastal, and Nyanza, parts of North Rift Valley and Western regions of the country. Occurrence of severe droughts in 1950s [19], were also reported. However, the drought events were infrequent over the decade. The severe droughts affected crop production leading to food insecurity in the ASALs in Kenya. Further, the food crop farmers recorded reduced incomes hence limited crop pro- 
duction in succeeding years. A notable increase in drought frequency was established in 1950s while 1960s experienced severe drought [20]. In addition, moderate drought was also monitored in Kenya in 1965 [14]. The occurrence of droughts in the 1960s was a major agricultural set-back for the ASALs in Kenya which are predominantly drought prone yet majority of the inhabitants depend on rain-fed crop production.

According to the following studies conducted in Kenya [19] and [20], severe droughts were experienced in early 1970s in Kenya. These droughts covered a large period of the decade indicating a significant increase in frequency of the droughts from the previous decade. Meanwhile, a cyclical nature of droughts in Kenya which was experienced in 1970s and 1980s was identified [17]. In addition, United Nations Development Programme found that the mid to the late 1970s experienced widespread droughts in Kenya [21]. Further, concurrence in the following studies [20] and [21] indicated that Kenya experienced drought in 1979/1980. Furthermore, severe droughts also occurred in early 1980s in Kenya [19]. Meanwhile, drought events are common phenomena in Kenya where persistent events were experienced between 1982 and 1993 [22]. In 1983/1984; widespread droughts were experienced in Eastern Kenya [17] and [21]. In concurrence with these findings, [14] also reported that Kenya experienced extreme drought in 1984 after the El Niño event.

Kenya experienced droughts in 1991/1992 in the ASALs in Northeastern, Eastern and Rift Valley regions [17]. Further, Kenya experienced four drought periods in 1991/1992, 1992/1993, 1995/1996 and 1998/2000 in the decade 1991 to 2000 [23] and [21]. The short return period is indicative of the increased effect of the phenomenon on crop production. Additionally, the 1990s experienced higher drought recurrence which was experienced in 1991, 1994, 1997 and 1999 [18]. Further, increase in regional expanse of droughts in Kenya over the mid- $20^{\text {th }}$ Century was also reported [2]. The frequent droughts in the mid- $20^{\text {th }}$ Century affected large populations of people as indicated in Table 1 [24] and [25].

The frequent drought trends indicated in Table 1 [24] and [25] had significant effects on the people in the affected areas in Kenya. Consistently high frequency of droughts in the decade spanning 2001 to 2010 was also recorded in Kenya [2] [24] and [25]. These droughts were near annual in occurrence and exhibited multi-year events of droughts from 2002 to 2010. Furthermore, occurrence of severe droughts in Kenya between 2000 and 2006 which resulted in widespread effects on millions of people was established as indicated in Table 1 [24] and [25]. Further, drought events were also reported in Kenya in 2004 [23]. In concurrence with these findings, [17] [20] and [21], also established occurrence of drought in 2004 and 2005 in Kenya. Further, 2006 was a major drought year in Kenya [2]. Meanwhile, a run in drought recurrence in the past decade of 2008 was pointed out [19]. Additionally, the country experienced droughts in Kenya in 2008 [17]. The continued drought trend was also recorded in Kenya where the country experienced droughts in 2008/2009 [23]. 
Table 1. Droughts in Kenya and number of people affected.

\begin{tabular}{cc}
\hline Year & Number of people affected \\
\hline 1975 & 16,000 \\
1977 & 20,000 \\
1980 & 40,000 \\
1984 & 200,000 \\
1992 & $1,500,000,000$ \\
$1995-1996$ & $1,400,000,000$ \\
$1999-2000$ & $4,400,000,000$ \\
$2004-2006$ & $3,500,000,000$ \\
\hline
\end{tabular}

Source: [24] and [25].

Increased frequency of droughts was experienced in Kenya from 2009 to 2011 [26]. However, weak droughts were experienced in Kenya in 2009 after an El Niño event [14]. Additionally, the declaration of the 2010 drought in Kenya as extreme was also revealed [27]. Notably, the high frequency of droughts at the beginning of the $21^{\text {st }}$ Century is a continuity of the high frequency of droughts pointed out at the end of the $20^{\text {th }}$ Century. In addition, the $21^{\text {st }}$ Century droughts were associated with El Niño events, climate variability and change which were consistent with increase in anthropogenic forcing.

A negative fluctuation in drought frequency was observed over the decade spanning 2011 to 2020. However, droughts were experienced in Kenya in 2010/2011 [3] where the 2011 drought was considered a major event [27]. Additionally, a near annual drought trend was recorded in Kenya in 2012 and 2016 [3]. Meanwhile, the second half of the decade experienced severe to extreme droughts where the 2016/2017 drought was declared as a national disaster and was regarded as an extreme event [27].

\section{Effects of Drought on Food Crop Production}

Droughts result in long-term deficit in water and high temperatures [28]. The low soil moisture and high soil and atmospheric temperatures limit crop growth and development and can limit crop yields at the phenological stages. Additionally, water stress and high temperatures experienced during drought periods negatively influence crop yields [3]. In concurrence with these findings, droughts in SSA triggered food crises due to deficit in water and extreme temperatures that impede crop growth and development hence decline in yields [15]. The study also reported that the biophysical and socioeconomic effects of droughts significantly affect food production in SSA. Meanwhile, an increase in the frequency of agricultural droughts by $50 \%$ to $100 \%$ by 2090 was also predicted [3]. The predicted increase in agricultural droughts are likely to negatively influence food crop production and lead to food insecurity if not timely and adequately checked. 
Even though, some crops such as sorghum and millet can withstand drought events, [29] reported a comparative decline in maize yields that was related to drought events on a global scale. The study also revealed a higher sensitivity of maize to droughts than wheat at the reproductive stages where yields are impaired. Occurrence and frequency of droughts limit the available soil moisture and increase the atmospheric temperatures which constrain crop water and soil nutrient absorption. Therefore, the pedo-climatic inhibitions on water and nutrients absorption by crops result in stunted crop growth and reduced yields.

Severe drought episodes were recorded in the last eight and a half decades in the HOA which significantly affected crop production [14]. Further, droughts were established to result in migration of farmers from the drought-prone regions in East Africa thereby leading to reduced farm labour [3]. The reduction in farm labour results in low crop production. Furthermore, the study reported a significant decline in income for crop farmers due to drought episodes in East Africa. Additionally, drought significantly limits growth and development of crop roots and other phenological processes and delays maturation therefore limiting crop yields hence food insecurity [15]. Further, apart from effects of drought on food crops, cash crops such as tea which accounts for $20 \%$ of the total exports earnings in Kenya are significantly affected by droughts where water stress leads to low yields [23]. The ASALs in Kenya that cover approximately $80 \%$ [16] of the entire surface area are prone to droughts which limit crop yields in the regions.

Even though agriculture is a vital sector of Kenya's economy, drought is a major limiting factor to crop production. The sector contributes $26 \%$ to the Gross Domestic Product while formally and informally employing $18 \%$ and $70 \%$ respectively [30]. Varying effects of droughts on different crops grown in Kenya was also indicated as significant [23]. The significant effect of drought was also established where the event was considered as the most common abiotic factor affecting crop production in Kenya [31]. The study also associated the risk of food insecurity in Kenya with the event. Additionally, droughts determine crop planting dates, weeding time, crop physiological development and nutrient composition besides the maturity time. Further, droughts cause crop loss due to water stress and development of new crop diseases and spread of pests which attack and destroy crops thereby limiting yields [26].

Even though Kenya experienced severe droughts in 1970s which resulted in low crop yields and affected about two million people [20], resilience to drought conditions by some crops such as sorghum and millet offered an opportunity for food security. Meanwhile, a cyclical nature of droughts in Kenya which was experienced in 1975, 1977 and 1980 where the events were accompanied by crop loss leading to famine was identified [17]. In addition, the mid to the late 1970s experienced widespread droughts in Kenya [21]. The widespread droughts had a negative effect on national crop yields occasioned by large food shortages in 1970s hence widespread food insecurity in the country. An occurrence of severe droughts in early 1980s was also reported [19], while persistent drought events 
in Kenya between 1982 and 1993 were also pointed out [22]. These persistent droughts in Kenya affected crop yield levels where massive crop loss was recorded. Furthermore, in 1983/1984, Kenya experienced widespread droughts that were accompanied by severe deficit in food supply and inaccessibility with approximately 200,000 people mostly in Eastern Kenya being affected [17] and [21]. In concurrence with these studies, [14] also found that Kenya experienced severe drought in 1984 where extreme droughts were experienced after the El Niño event leading to massive crop loss. The frequent severe droughts in 1980s resulted in large food deficits in Kenya which led to relief food importation as indicated in Table 2.

Weak droughts were experienced in Kenya in 1991 after the El Niño event [14]. These droughts extended to 1992 where the ASALs in Northeastern, Eastern and Rift Valley regions experienced significant effects including food insecurity experienced by 1.5 million people due to decline in crop yields [17]. Kenya also experienced frequent droughts from 1991 to 2000 [23] and [21]. The

Table 2. Chronology of drought incidences in Kenya since 1950.

\begin{tabular}{|c|c|c|}
\hline Date & Region & Remarks \\
\hline 1950 & $\begin{array}{l}\text { Central, Coast, Eastern, Nyanza, } \\
\text { Western and Rift Valley Province }\end{array}$ & Very Severe in Coast \\
\hline $1952-1955$ & $\begin{array}{l}\text { Eastern, South/North of Rift Valley } \\
\text { Province }\end{array}$ & $\begin{array}{l}\text { Droughts followed by floods, cattle } \\
\text { mortality at about } 70 \%-80 \% \text { in } \\
\text { Maasai land }\end{array}$ \\
\hline $1960-1961$ & Widespread & $\begin{array}{l}\text { Rains about } 50 \% \text { long-term mean, } \\
\text { Nairobi water shortage, wildlife } \\
\text { death in Nairobi National Park }\end{array}$ \\
\hline 1972 & Most of Kenya & $\begin{array}{l}\text { Human and Livestock death in } \\
\text { the Northern Districts, Maasai } \\
\text { cattle losses about } 80 \%\end{array}$ \\
\hline $1973-1974$ & Eastern, Central, Northern Regions & Crop production paralyzed \\
\hline 1974-1976 & Central, Eastern, Western, Coast & $\begin{array}{l}\text { Famine in Eastern Province, water } \\
\text { shortages, migration of people and } \\
\text { livestock, large food deficits }\end{array}$ \\
\hline 1980 & Eastern Province & Large food deficits \\
\hline $1981-1983$ & Countrywide & $\begin{array}{l}\text { Severe food shortages in Eastern } \\
\text { Province, less in Central Province }\end{array}$ \\
\hline 1984 & $\begin{array}{l}\text { Central, Rift Valley, Eastern and } \\
\text { North Eastern }\end{array}$ & $\begin{array}{l}\text { Moderately severe in Eastern } \\
\text { Province, relief food imported }\end{array}$ \\
\hline 1987 & Eastern and Central & $\begin{array}{l}4.7 \text { million people dependent on } \\
\text { relief food, power and water } \\
\text { rationing }\end{array}$ \\
\hline $1992-1994$ & Northern, Central, Eastern Provinces & \\
\hline $1999-2000$ & $\begin{array}{l}\text { Countrywide except West } \\
\text { and Central belt }\end{array}$ & \\
\hline
\end{tabular}

Source: Adapted from [7], as modified by [33]. 
increased frequency of droughts in 1990s significantly affected crop yields in Kenya. Moreover, increase in cases of droughts in Kenya over the mid- $20^{\text {th }}$ Century was also reported [2]. The increased frequency of droughts in the ASALs of Kenya was compounded by food insecurity over the decade due to the low seasonal rainfall and low soil moisture resulting from near annual droughts. Additionally, in 1995/1996 Kenya experienced drought where approximately 1.4 million people suffered food insecurity [17]. In 1998, an increase in drought runs which span a decade in Kenya was registered [19]. Increased effects of drought were also experienced in 1999/2000 where 4.4 million people were affected in Kenya [17]. Meanwhile, [32] established that the 1999/2000 drought in Kenya was registered as the most severe event in the past 50 years. In addition to the resulting crop loss and loss of human lives, droughts limited the availability of farm labour and disposable income resulting in decline in food crop production. Further, the 2000 drought in Kenya [20], was the most severe in 37 years thereby affecting about four million people in the country. Relative to theses droughts, it is noteworthy that the 1990s was the most drought-prone period in the entire period under study. The frequent droughts therefore increased lag time and resulted in adverse pedo-climatic conditions that impeded crop production with severe effects in Kenya as indicated in Table 2.

In the 2000s, Kenya experienced droughts annually [2]. Major droughts occurred in Kenya in 2003/2004 where approximately 2.23 million people suffered famine events [16]. The negative effects of droughts were elaborated by UNDP (2005) and [20] who revealed that the 2004 drought in Kenya led to crop failure and food insecurity. Meanwhile, approximately 3 million people were affected by droughts in Kenya in the same year [17]. Further, 2006 was a major drought year in Kenya with 2.97 million people affected [16] while a drop in crop yield was reported in the same year [2]. Additionally, 1.4 million people were affected by droughts in 2008, while 10 million people experienced famine in Kenya in 2009 [17]. However, weak droughts were experienced in Kenya in 2009 after an El Niño event [14]. Besides, droughts experienced in Kenya from 2009 to 2011 caused decline in sorghum yields thereby a significant increase in food insecurity was recorded in the country [26]. In 2010, an extreme drought occurred in Kenya leading to devastating crop loss [27].

Significant effects of droughts [33] were established to have affected a large population in Kenya. Additionally, the studies established mortalities resulting from droughts in the country. Further, the studies indicated that large numbers of livestock was also affected in addition to a similarly large spatial extent that was affected by drought thereby leading to loss of crops hence famine in the country.

During the 2010/2011 droughts in Kenya, crop production was severely affected [3] and [27]. In addition, about 3.75 million people were affected during the 2011drought event [16]. Meanwhile, in 2012, 30\% loss in crop yields was experienced in Kenya due to droughts [3]. Moreover, droughts occurred in Kenya in 2012 and 2016 [3]. These drought events had significant effect on crop pro- 
duction in Kenya. Meanwhile, the 2016/2017 drought was declared a national disaster which was also regarded as an extreme event in Kenya [27]. The occurrence of severe to extreme droughts over the decade resulted in low crop yields hence food insecurity most particularly in the affected ASALs. The study also indicated that in 2016, drought resulted in crop loss thereby affecting about 3 million people in the country. Even though the droughts experienced in Kenya from 2011 to 2020 severely affected crop production and a large population, there was a notable decline in the frequency of droughts over the decade.

\section{Conclusion}

Drought severity and recurrence indicated fluctuating patterns in different parts of the world thereby indicating a high uncertainty in global-scale trends in the past 60 years. Severe droughts were experienced in the 1990s and 2000s at the global scale. However, moderate droughts were experienced in all the continents in the $20^{\text {th }}$ Century. Some regions of the world such as Sahel region of Africa indicated increasing drought trends and projections of drought increase in frequency and severity; hence were considered drought hot spots. Africa was also identified as the most drought-vulnerable region in the world. Minimal drought events were noted in 1950s in Kenya; however an increasing drought trend was established in the succeeding decade. A notable continuous increase of drought frequency from the previous decade was recorded in Kenya in the 1970s. Meanwhile, a decrease in drought events was observed in the country in 1980s. In the 1990s and 2000s, there was a significant increase in drought frequency in Kenya which decreased slightly in 2010s. Relatively low crop yields were hence recorded with increase in drought frequency in Kenya. The increased frequency and severity in drought events in the last two decades significantly affected crop yields leading to food insecurity in the country. Severe droughts and resulting famine and food insecurity resulted in loss of human lives. Loss of livestock was also experienced. The study identified limited information on decadal causes and recurrence of droughts and inadequate explanation on why 1950 to 2020 experienced increase in drought occurrence in Kenya.

\section{Conflicts of Interest}

The authors declare no conflicts of interest regarding the publication of this paper.

\section{References}

[1] Brázdil, R., Kiss, A., Luterbacher, J., Nash, D. and Řezníčková, L. (2018) Documentary Data and the Study of Past Droughts: A Global State of the Art. Climate of the Past, 14, 1915-1960. https://doi.org/10.5194/cp-14-1915-2018

[2] Food and Agriculture Organization of the United Nations (FAO) (2013) Drought. FAO Land and Water. http://fao.org/3/aq191e/aq191e.pdf

[3] Haile, G., Tang, Q., Sun, S., Huang, Z. Zhang, X. and Liu, X. (2019) Droughts in East Africa: Causes, Impacts and Resilience. Earth-Science Reviews, 193, 146-161. 
https://doi.org/10.1016/j.earscirev.2019.04.015

[4] Simtowe, F. and Mausch, K. (2019) Who Is Quitting? An Analysis of the Dis-Adoption of Climate Smart Sorghum Varieties in Tanzania. International Journal of Climate Change Strategies and Management, 11, 341-357. https://doi.org/10.1108/IJCCSM-01-2018-0007

[5] Adhikari, U., Nejadhashemi, A.P. and Woznicki, A.S. (2015) Climate Change and Eastern Africa: A Review of Impact on Major Crops and Energy Security. Food and Energy Security, 4, 110-132. https://doi.org/10.1002/fes3.61

[6] Msongaleli, B., Rwehumbiza, F.B.R., Tumbo, S.D. and Kihupi, N. (2013) Investigation of Sorghum Yield Response to Variable and Changing Climatic Conditions in Semi-Arid Central Tanzania: Evaluating Crop Simulation Model Applications. African Crop Science Conference Proceedings, 11, 899-909.

[7] Liu, W., Sun, F., Lim, W., Zhang, Z., Wang, H., Shiogama, H. and Zhang, Y. (2018) Global Drought and Severe Drought-Affected Populations in 1.5 and $2.0^{\circ} \mathrm{C}$ Warmer Worlds. Earth System Dynamics, 9, 267-283.

https://doi.org/10.5194/esd-9-267-2018

[8] Seneviratne, S. (2012) Climate Science: Historical Drought Trends Revisited. Nature, 491, 338-339. https://doi.org/10.1038/491338a

[9] Ficklin, L, Justin, T., Letsinger, L. and Gholizadeh, H. (2015) A Climatic Deconstruction of Recent Drought Trends in the United States. Center for Geospatial Data Analysis, Indiana Geological Survey, Bloomington. Environmental Research Letters, 10, Artice ID: 044009. https://doi.org/10.1088/1748-9326/10/4/044009

[10] Intergovernmental Panel on Climate Change (IPCC) (2014) Climate Change 2014: Synthesis Report. Contribution of Working Groups I, II and III to the Fifth Assessment Report of the Intergovernmental Panel on Climate Change. [Core Writing Team, Pachauri, R.K. and Meyer, L.A. (Eds.)]. Intergovernmental Panel on Climate Change, Geneva, 151 p. http://www.ipcc.ch

[11] Krakauer, N., Lakhankar, T. and Hudson, D. (2019) Trends in Drought over the Northeast United States Water, 11, Article No. 1834.

https://doi.org/10.3390/w11091834

[12] Masih, I., Maskey, S., Mussá, F. and Trambauer, P. (2014) A Review of Droughts on the African Continent: A Geospatial and Long-Term Perspective. Hydrology and Earth System Sciences, 18, 3635-3649. https://doi.org/10.5194/hess-18-3635-2014

[13] McCabe, G. and Wolock, D. (2015) Variability and Trends in Global Drought. Earth and Space Science, 2, 223-228. https://doi.org/10.1002/2015EA000100

[14] Ghebrezgabher, M., Yang, T. and Yang, X. (2016) Long-Term Trend of Climate Change and Drought Assessment in the Horn of Africa. Advances in Meteorology, 2016, Article ID: 8057641. https://doi.org/10.1155/2016/8057641

[15] He, X., Estes, L., Konar, M., Tian, D., Anghileri, D., Baylis, K., Evans, T.P. and Sheffield, J. (2019) Integrated Approaches to Understanding and Reducing Drought Impact on Food Security Across Scales. Current Opinion in Environmental Sustainability, 40, 43-54. https://doi.org/10.1016/j.cosust.2019.09.006

[16] Venton, C. (2018) Economics of Resilience to Drought: Kenya Analysis. https://www.usaid.gov/sites/default/files/documents/1867/Kenya_Economics_of_Re silience_Final_Jan_4_2018_-_BRANDED.pdf

[17] Mateche, D. (2011) The Cycle of Drought in Kenya: A Looming Humanitarian Crisis. Institute for Security Studies, Pretoria.

https://issafrica.org/iss-today/the-cycle-of-drought-in-kenya-a-looming-humanitari an-crisis 
[18] Nyaoro, D., Schade, D. and Schmidt, K. (2016) Assessing the Evidence: Migration, Environment and Climate Change in Kenya. International Organization for Migration (IOM), Geneva.

https://www.preventionweb.net/files/50534_assessingtheevidencekenya.pdf

[19] Onyango, O.A. (2014) Analysis of Meteorological Drought in North Eastern Province of Kenya. Journal of Earth Science Climate Change, 5, Article No. 219.

[20] Kandji, S.T. (2006) Drought in Kenya: Climatic, Economic and Socio-Political Factors. Today, 17-19.

[21] United Nations Development Program (UNDP) (2005) Kenya Natural Disaster Profile. Enhanced Security Unit.

https://meteorology.uonbi.ac.ke/sites/default/files/cbps/sps/meteorology/Project\%2 0on\%20Disasters.pdf

[22] Recha, C. (2013) Effects of Climate Variability on Water Resources and Livelihoods and State of Adaptive Capacity in Semi-Arid Tharaka District, Kenya. A Thesis Submitted to Kenyatta University, Kenyatta.

[23] Ochieng, J., Kirimi, L. and Mathenge, M. (2016) Effects of Climate Variability and Change on Agricultural Production: The Case of Small Scale Farmers in Kenya. NJAS- Wageningen Journal of Life Sciences, 77, 71-78. https://doi.org/10.1016/j.njas.2016.03.005

[24] Ngaira, J.K. (2004) Basic Facts in Contemporary Climatology. Lake Publishers and Enterprises, Kisumu.

[25] Oxfam (2006) Kenya Crisis 2006-Background.

https://oxfamilibrary.openrepository.com/bitstream/handle/10546/114545/bp89-ma king-the-case-kenya-160506-en.pdf;jsessionid=B568537BD50D1245F11FCC295DC 69E26? sequence $=1$

[26] Gichure, R.W. (2017) Effects of Drought on Crop Production and Coping Mechanisms Undertaken by Small-Scale Farmers: A Case of Makueni County, Kenya. A Thesis Submitted to University of Nairobi, Nairobi.

[27] Uhe, P., Sjoukje, P., Bilt, D., Kew, S., Shah, K., Kimutai, J., Otto, F., Oldenborgh, G. J. V., Singh, R., Arrighi, J. and Cullen, H. (2017) The Drought in Kenya 2016-2017. Climate and Development Knowledge Network and World Weather Attribution Initiative. Raising Risk Awareness.

https://www.alnap.org/system/files/content/resource/files/main/The-drought-in-Ke nya-2016-2017.pdf

[28] Food and Agriculture Organization of the United Nations (FAO) (2018) The Impact of Disasters and Crises on Agriculture and Food Security. Food and Agriculture Organization of the United Nations, Rome.

[29] Daryanto, S., Wang, L. and Jacinthe, P-A. (2016) Global Synthesis of Drought Effects on Maize and Wheat Production. PLoS ONE, 11, e0156362.

https://doi.org/10.1371/journal.pone.0156362

[30] Mwadalu, R. and Mwangi, M. (2013) The Potential Role of Sorghum in Enhancing Food Security in Semi-Arid Eastern Kenya: A Review. Journal of Applied Biosciences, 71, 5786-5799. https://doi.org/10.4314/jab.v71i1.98826

[31] Ogeto, R.M., Mshenga, P., Cheruiyot, E. and Onyari, C.N. (2012) Influence of institutional Factors on Sorghum Production in Nakuru District, Kenya. Journal of Agricultural Economics and Development, 1, 130-137.

[32] Karanja, A.M. (2013) Analysis of Rainfall Variability on Irish Potato Production in Ol-Joro-Orok Division, Nyandarua County, Kenya. Asian Journal of Applied Sciences, 2. 
[33] Gathara (1995) As Modified by United Nations Environment Programme (UNEP) and Government of Kenya (GOK) (2000) Devastating Drought in Kenya: Environmental Impacts and Responses. United Nations Environment Programme. Nairobi. 